\title{
Preface to the Philosophy of Emotions
}

\author{
Aaron Ben-Ze'ev ${ }^{1}$
}

Published online: 17 March 2018

(C) Springer Science+Business Media B.V., part of Springer Nature 2018

Emotions are multifaceted and constitute perhaps the most complex mental phenomena. The topic of the emotions, Rene Descartes said, does not seem to be one of the more difficult to investigate, since everyone feels emotions, and so we have no need to look far to observe and establish their nature. Nevertheless, Descartes thought that previous writings about this topic were so confused that rather than relying on them, he made a conscious decision to write about emotions as if he were examining a topic with which no one had previously dealt. Descartes' approach to this topic expresses two seemingly conflicting aspects of emotions: simplicity and complexity. The simplicity of emotions appears to be evident, as Descartes noted, in the fact that people feel them firsthand and need not look elsewhere to be aware of them. The complexity of emotions is illustrated in the ambiguity in previous writings on the topic, a fact that deterred Descartes from relying on them.

The simple and complex aspects of emotions relate to the claim that emotions are Janus-faced, revealing something about the world and about ourselves. Accordingly, we might discern two kinds of truths in emotions; one is about the self and the other about the world (de Sousa, 2007/2017). Each of us has direct, and often, privileged, access to the former kind of information, so attaining this information seems to be simple; revealing the information on the latter type is complex and requires profound, intricate intellectual deliberations.

In light of this duality, discussion on emotions can profit, as indeed is the case with the articles presented in this special issue, from various commonsense sources, such as conversations with lay people, novels and other aesthetic forms, popular culture, and other everyday sources, none of which were created with the aim of investigating or understanding the emotions. References to these sources is not intended to provide any conclusive proof for the arguments, as such a proof needs also be based on intellectual considerations; however, these all provide good indications of the way people think about emotions. Even if such lay beliefs tend to be imprecise or partly mistaken, such

Aaron Ben-Ze'ev

abenzeev@univ.haifa.ac.il

1 Department of Philosophy, University of Haifa, Haifa, Israel 
beliefs do tell us something about emotions and the way we treat them. Thus, when a popular love song declares that "you are everything and everything is you," this claim is, no doubt, lyric exaggeration, since each of us has various sorts of meaning and things that are dear to us. However, this exaggeration expresses the focus (though not the exclusive focus) of the lover; it also highlights a prevailing myth in our culture about romantic love. Revealing the focus and the myth helps us to better understand this emotion we call romantic love.

In light of the enormous complexity and diversity of emotions, organizing our commonsense knowledge into a comprehensive conceptual framework is difficult and often complex. This is, of course, no reason to neglect trying to provide such a framework, but it does impose certain constraints on doing so.

Notwithstanding Descartes's attitude, contemporary research into the philosophy of emotions has gained a great deal from earlier writings, as the articles in this issue clearly show. In this regard, I adopt the attitude expressed by the German psychologist Carl Stumpf (1899: 67), who claimed that being influenced by previous thinkers can reduce the surprise value of our own theory, but while absolute originality in matters that are open to introspection at all times might demonstrate the author's inventiveness, it unlikely to endorse his or her case.

The apparent simplicity of emotions, as well as their personal and practical concerns, could be the reason why historically, the study of emotions has not been central in philosophical discussions. Although all major philosophers, including Plato, Aristotle, Descartes, Spinoza, Kant, Wittgenstein, and Sartre, discuss the emotions at some length, it has not occupied as much of a dominant focus in philosophy as other issues in the philosophy of mind. The complexity of emotions has deterred many psychologists from making this subject central in psychology. A main reason for this is a lack of accurate and quantitative measures for establishing the diverse and complex features of emotions. It is no wonder that the best descriptions of emotions have been provided by artists, rather than psychologists or philosophers. The works of artists are based on their personal and unique perspectives, which is precisely the perspective of the agent who experiences the emotions.

Interest in the psychology of emotions has increased with the development of various tools for measuring emotion. Such progress is particularly significant in neuroscience, which can detect brain activities that are correlated to mental phenomena. This has also led other related social sciences to take a deeper the interest in the emotions.

In the last few decades, the general rise in interest in emotions is evident also in philosophy, where an increasing number of philosophers are focusing their research on the study of the emotions. Compatible with this interest is the establishment of the European Philosophical Society for the Study of Emotions. Interest in the emotions has produced many philosophical books on the emotions. I list here only a few of anthologies on philosophy of emotions from the last two decades: French \& Wettstein, 1999; Hatzimoysis, 2003; Solomon, 2004; Döring, 2009; Merker, 2009; Goldie, 2010; Ben-Ze'ev \& Krebs, 2017; Szanto \& Landweer, 2019). The recent special issue of Philosophia on the Meaning of Moods (2017) and the current issue on The Philosophy of Emotions further express the growing importance of emotions and moods in contemporary philosophy.

This special issue on The Philosophy of Emotions includes studies on various aspects of emotions, focusing first on the nature of emotions, continuing with 
articles on emotions and aesthetics, and concluding with discussions on specific emotions.

All the papers included in this issue have undergone the ordinary Philosophia procedure of review and revision run by the Editor in Chief.

\section{References}

Ben-Ze'ev, A., \& Krebs, A. (Eds.). (2017). Philosophy of emotion, four Volumes. London: Routledge. de Sousa, R. (2007/2017). Truth, authenticity, and rationality of emotions, in A. Krebs \& A. Ben-Ze'ev, (eds.)

(2017). Philosophy of emotion, Vol. III, London: Routledge, pp. 251-272.

Döring, S. A. (Ed.). (2009). Philosophie der Gefühle. Frankfurt: Suhrkamp.

French, P. A., \& Wettstein, H. K. (Eds.). (1999). Philosophy of emotions. Notre Dame: University of Notre Dame Press.

Goldie, P. (Ed.). (2010). The Oxford handbook of philosophy of emotion. Oxford: Oxford University Press. Hatzimoysis, A. (Ed.). (2003). Philosophy and the emotions. Cambridge: Cambridge University Press.

Merker, B. (Ed.). (2009). Leben mit Gefuhlen. Paderborn: Mentis.

Solomon, R. C. (Ed.). (2004). Thinking about feeling. Oxford: Oxford University Press.

Stumpf, C. (1899). Uber den Begriff der Gemuthsbewegung. Zeitschrift fur Psychologie und Physiologie der Sinnesorgane, 21, 47-99.

Szanto, T., \& Landweer, H. (Eds.). (2019). Handbook on phenomenology of emotions. London: Routledge. 